\title{
Definition and Prevalence of Peri-Implantitis
}

\author{
Georgios Charalampakis • Erika Jansåker • \\ Ann-Marie Roos-Jansåker
}

Published online: 14 September 2014

(C) Springer International Publishing AG 2014

\begin{abstract}
This narrative review focuses on the current understanding of the definition and prevalence of peri-implantitis. A MEDLINE (PubMed) search over the past 3 years was performed using keywords related to the definition and prevalence of peri-implantitis. Additional literature retrieved from reference lists, review articles, and consensus reports were used. Definition of peri-implantitis is heterogeneous due to the various thresholds of bone loss and pocket depths used, creating a discrepancy in the prevalence figures. The prevalence of peri-implant mucositis varied between 19 and $65 \%$, whereas the prevalence of peri-implantitis ranged from 10 to $40 \%$. A consensus has been reached that the definition of peri-implantitis should be clinical signs of inflammation (bleeding on probing) and/or suppuration, in combination with progressive bone loss. In addition, we strongly recommend that measurement of the bone loss in relation to the implant length would further classify the case as mild, moderate, or severe peri-implantitis.
\end{abstract}

Keywords Peri-implantitis - Peri-implant mucositis · Definition · Prevalence

G. Charalampakis

Department of Oral Microbiology and Immunology, Institute of Odontology, The Sahlgrenska Academy at University of

Gothenburg, Gothenburg, Sweden

E. Jansåker

Department of Odontology, School of Dentistry, Faculty of Health and Medical Sciences, University of Copenhagen, Copenhagen, Denmark

\section{A.-M. Roos-Jansåker $(\bowtie)$}

Department of Periodontology, Public Dental Health Service,

Kristianstad, Sweden. Tandvårdshuset, Axel Kleimers väg 2, 291

33 Kristianstad, Sweden

e-mail: Ann-Marie.Jansaker@skane.se

\section{Introduction}

The introduction of the biological concept of osseointegration [1] led to the development of endosseous root-formed implants, a revolutionary alternative in restorative dentistry. The highly successful use of osseointegrated dental implants to restore partial and full edentulism has been documented in a wealth of scientific literature [2-5]. According to available statistics, the number of dental implants installed annually around the world exceeds 2 million [6]. Just as the total population of the world is growing, and given that implant placement has become a routine treatment modality in daily clinical practice by specialists as well as by general practitioners, this number is expected to rise. The excellent success rates for dental implants presented in the literature lie in the fact that the criterion for failure has been implant loss, the terminal result of complete loss of osseointegration. Given the successful initial osseointegration, it is difficult to believe that implant loss is the result of a sudden burst without intermediate events. Thus, long-term biological complications around dental implants do occur and should be monitored by clinicians.

For more than three decades we have witnessed the emergence of two new diseases, peri-implant mucositis and periimplantitis. These pathological conditions are considered to be major complications and draw significant attention in the literature. The term peri-implantitis was introduced to stress the infectious nature of the pathological conditions around peri-implant tissues $[7,8]$. The consensus report from the 1st European Workshop on Periodontology [9] defined periimplantitis as an irreversible inflammatory destructive reaction around implants in function, accompanied by loss of supporting bone. The 6th European Workshop on Periodontology presented modified definitions, not only to acknowledge that peri-implantitis is a treatable condition but also to include the collective term peri-implant disease for both 
entities, i.e., peri-implant mucositis and peri-implantitis [10]. Peri-implant mucositis was defined as a reversible inflammatory reaction in the soft tissues surrounding an implant in function, whereas peri-implantitis was defined as a more profound inflammatory lesion characterized by a deepened peri-implant pocket and loss of supporting bone around a functional implant. These two disorders are biofilmmediated diseases developing in a fashion similar to the diseases occurring in the natural dentition. Mucositis corresponds to gingivitis and peri-implantitis is analogous to periodontitis $[11 \cdot 12]$.

Disease definition is quite different from a case definition. Despite the very clear and comprehensive disease definition, inconsistencies and confusion emerge when the terminology is applied in clinical practice. The variance in prevalence of peri-implantitis in studies available up to 2010 was the result of inconsistent case definitions [13, 14, 15•, 16, 17]. Koldsland et al. [15•] and Roos-Jansåker et al [17] demonstrated that the freedom to accept different thresholds of disease in the terminology had a direct impact on the prevalence of peri-implantitis.

This narrative systematic review encompasses the available literature since 2011, with the aims of identifying the core problem in defining peri-implant disease and elucidating how this affects the reports on prevalence in the studied populations.

\section{Materials and Methods}

All three authors performed an electronic search of the MEDLINE database via PubMed to find relevant articles using the following terms alone or in combination: peri-implant disease, peri-implant mucositis, peri-implantitis, periimplantitis, definition, prevalence, epidemiology. Articles were eligible if they reported data in the English language. In addition, a hand search was carried out to include reference lists as well as systematic reviews. While prospective longitudinal studies were eligible for the incidence of peri-implant disease, cross-sectional studies were considered for the assessment of prevalence. Focus was placed on recent studies, published in 2011 and later, so as to provide the reader with up-to-date information. All cross-sectional studies presenting a clear case definition for peri-implant disease and reporting prevalence data on a subject level are highlighted as being of importance (•) among the included studies. Studies since 2010 that are classical or exceptional in their methodology and concluding remarks were highlighted as being of major importance $(\bullet)$.

\section{Results}

The final results of the electronic search are summarized in Tables 1 and 2. Table 1 includes articles related to the focused question 'Definition and prevalence of peri-implantitis' and provides the aim of the study, the prevalence of mucositis and peri-implantitis (where available), as well as a comment on the major findings. Table 2 provides the most recent literature review articles related to the focused question.

\section{Case Definitions for Peri-Implant Disease}

Case definitions for peri-implant mucositis and periimplantitis are discussed separately. Note that studies included in the case definitions do not necessarily focus on prevalence, but could focus on risk factors $[18,19]$ or biological markers associated with pathogenesis [20]. The rationale for including such studies was to show the variance in case definitions in published studies.

\section{a) Peri-Implant Mucositis}

In most studies, the case definition for peri-implant mucositis is either not presented or is extracted directly from the terminology. Thus, mucositis was defined as visual inflammation and bleeding on probing (BoP) with no/slight bone loss [18, 20, 21•, 22, 23•, 24, 25•, 26, 27•, 28•, 29•]. However, the threshold for acceptable bone levels was further defined in some of the studies. In one, the marginal bone level was defined as the number of threads [25•]. Specifically, peri-implant mucositis was defined as presence of $\mathrm{BoP}$ and a bone level of $<2$ threads. A drawback of this study was that different implant systems were used and the variability in inter-thread distances cannot be neglected. In another study [27•], bone level was presented in millimeters and mucositis involved the presence of BoP, probing pocket depth (PPD) $\leq 5 \mathrm{~mm}$, and a bone level of $\leq 2 \mathrm{~mm}$. In other studies [28•, 29•], bone loss was assessed and mucositis was defined as the presence of BoP and a threshold of bone loss $\leq 0.5 \mathrm{~mm}$.

b) Peri-Implantitis

In some studies, lack of clear case definitions was obvious since radiological assessments were made alone without any clinical registrations. In a cross-sectional study [24] and in two prospective cohort studies [30, 31], the threshold of $\geq 3 \mathrm{~mm}$ bone loss was considered to be associated with pathology without reporting on clinical parameters.

In a few studies [32, 33], clinical registrations were used alone to assess biological complications, i.e., periimplantitis. Whereas BoP was a prerequisite as a finding for these two studies, the threshold for PPD varied significantly, i.e., PPD $>3 \mathrm{~mm}$ [32] and PPD $>4 \mathrm{~mm}$ [33].

In most studies, a combination of clinical and radiological measurements was used for case definition. Four studies assessed bone levels in the definition of periimplantitis [23•, 25•, 27•, 34•]. Costa et al. [23•] and Dvorak et al. [34•] required BoP and/or suppuration 


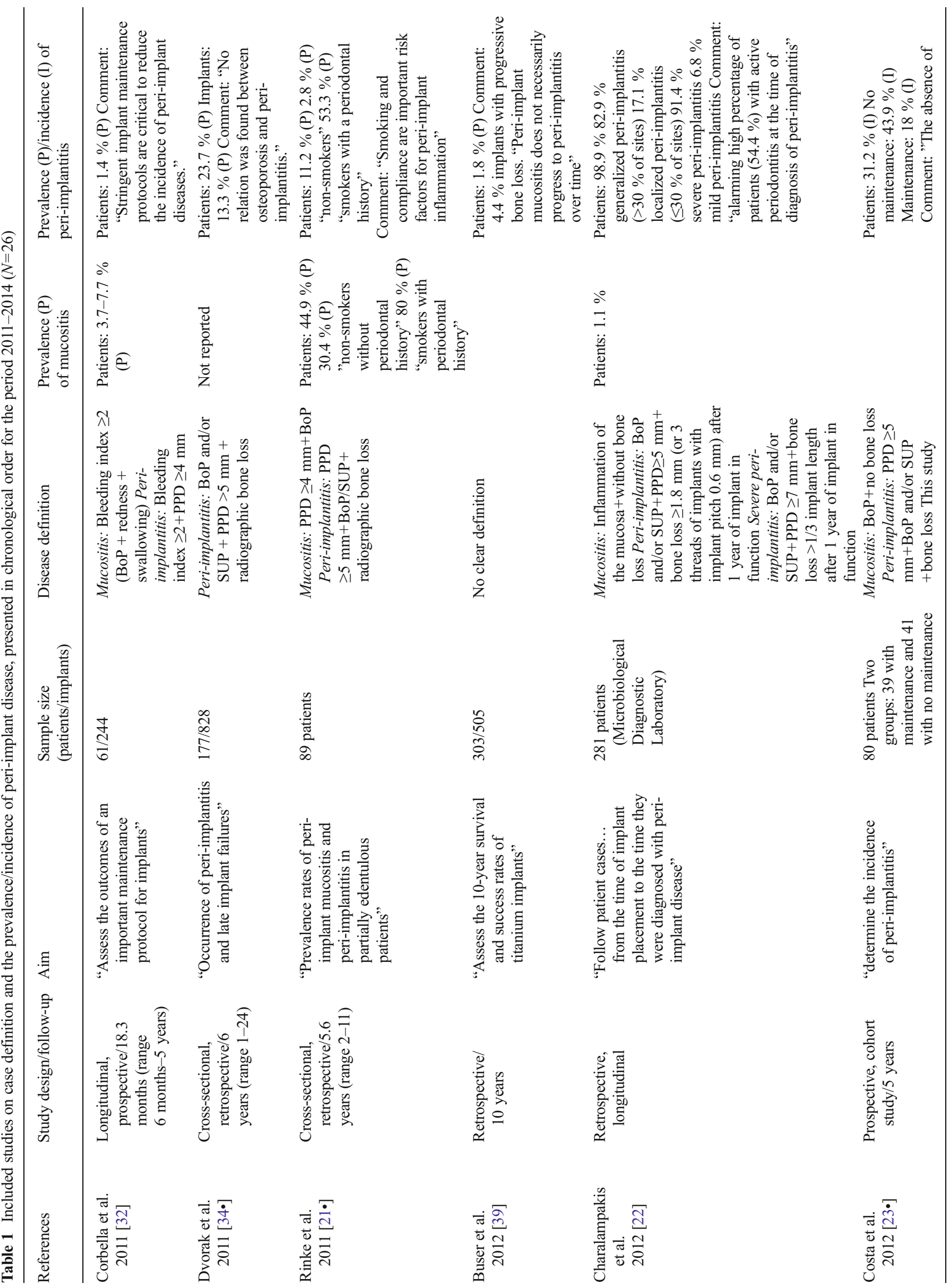




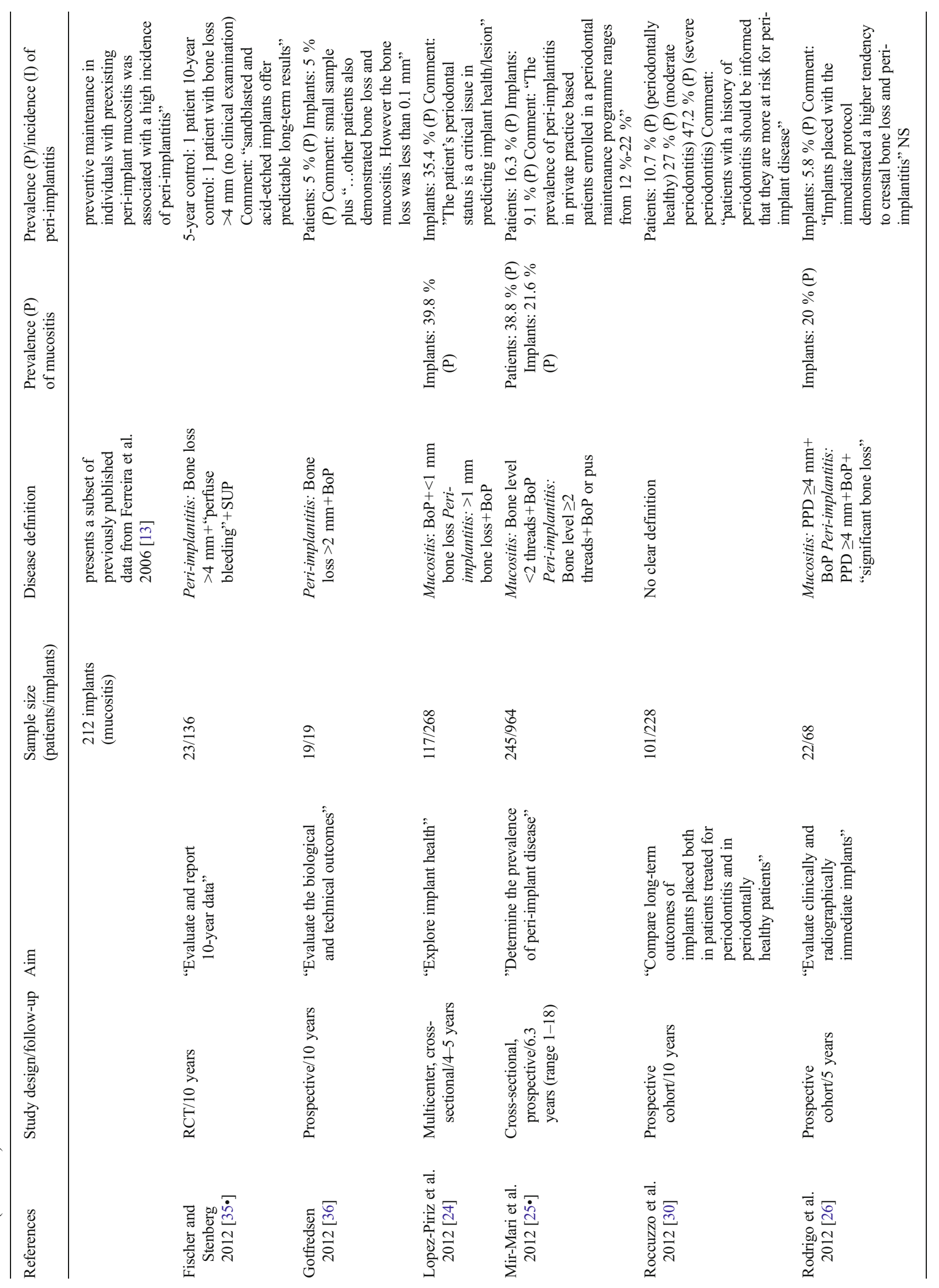




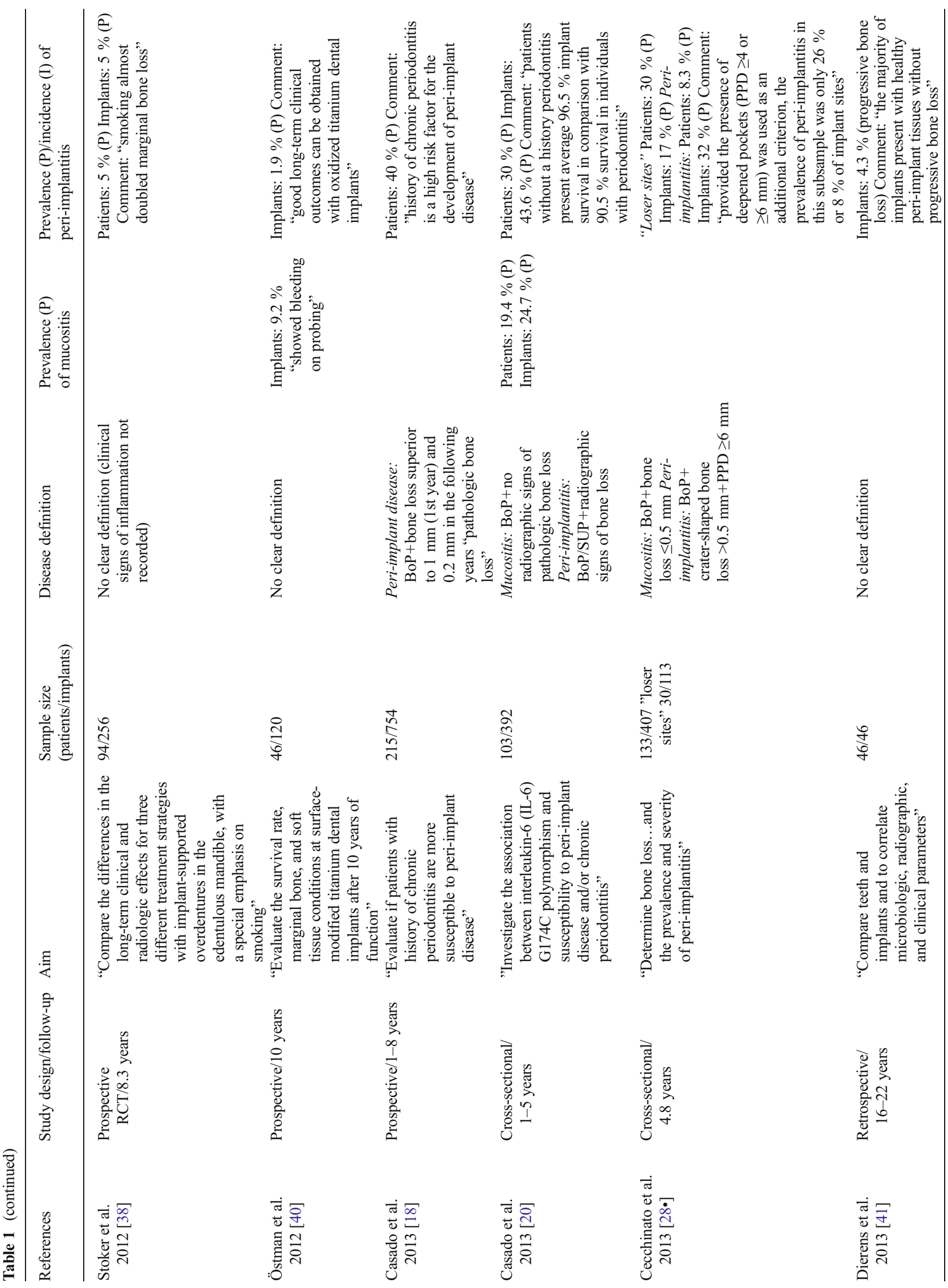




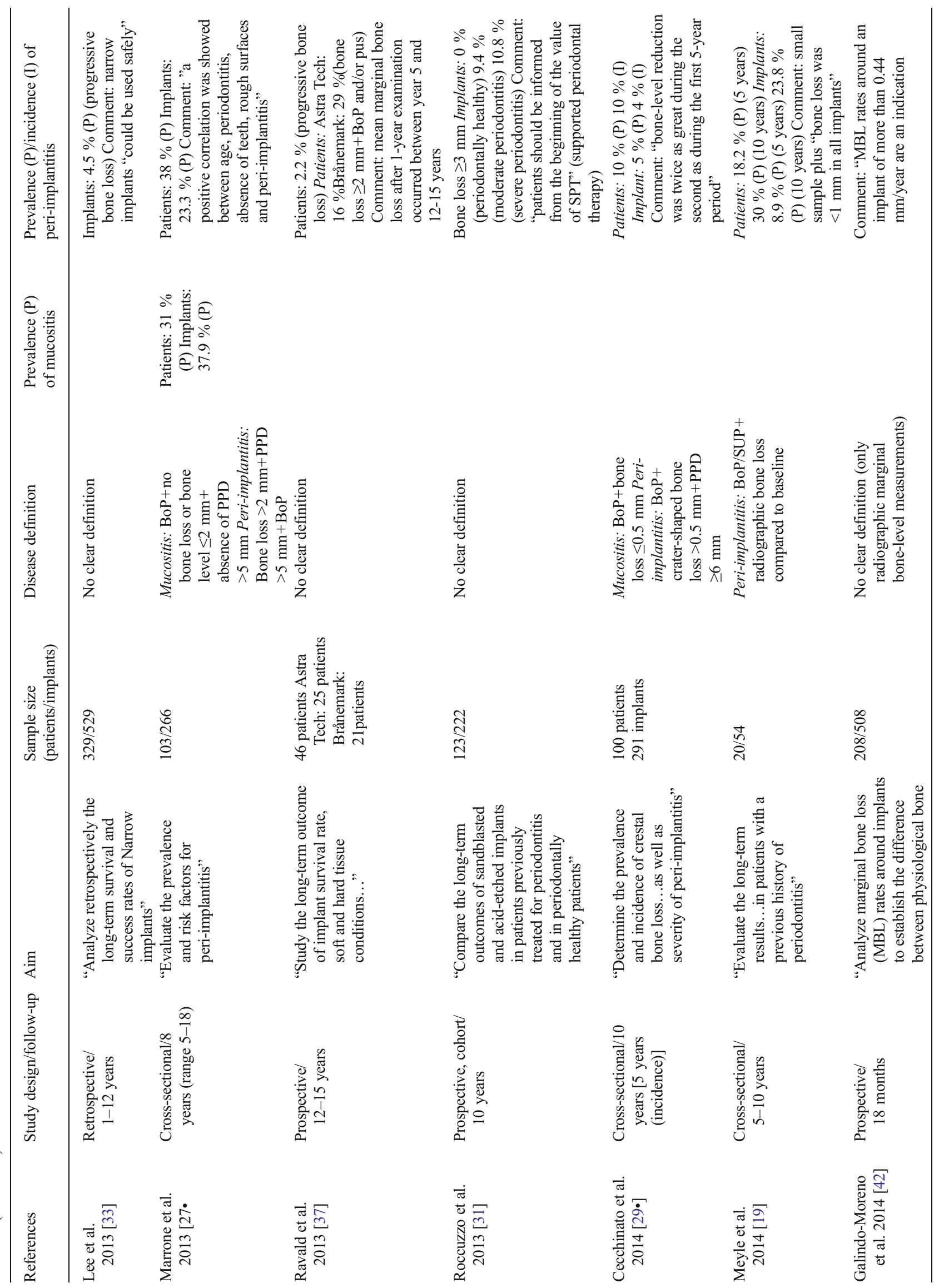




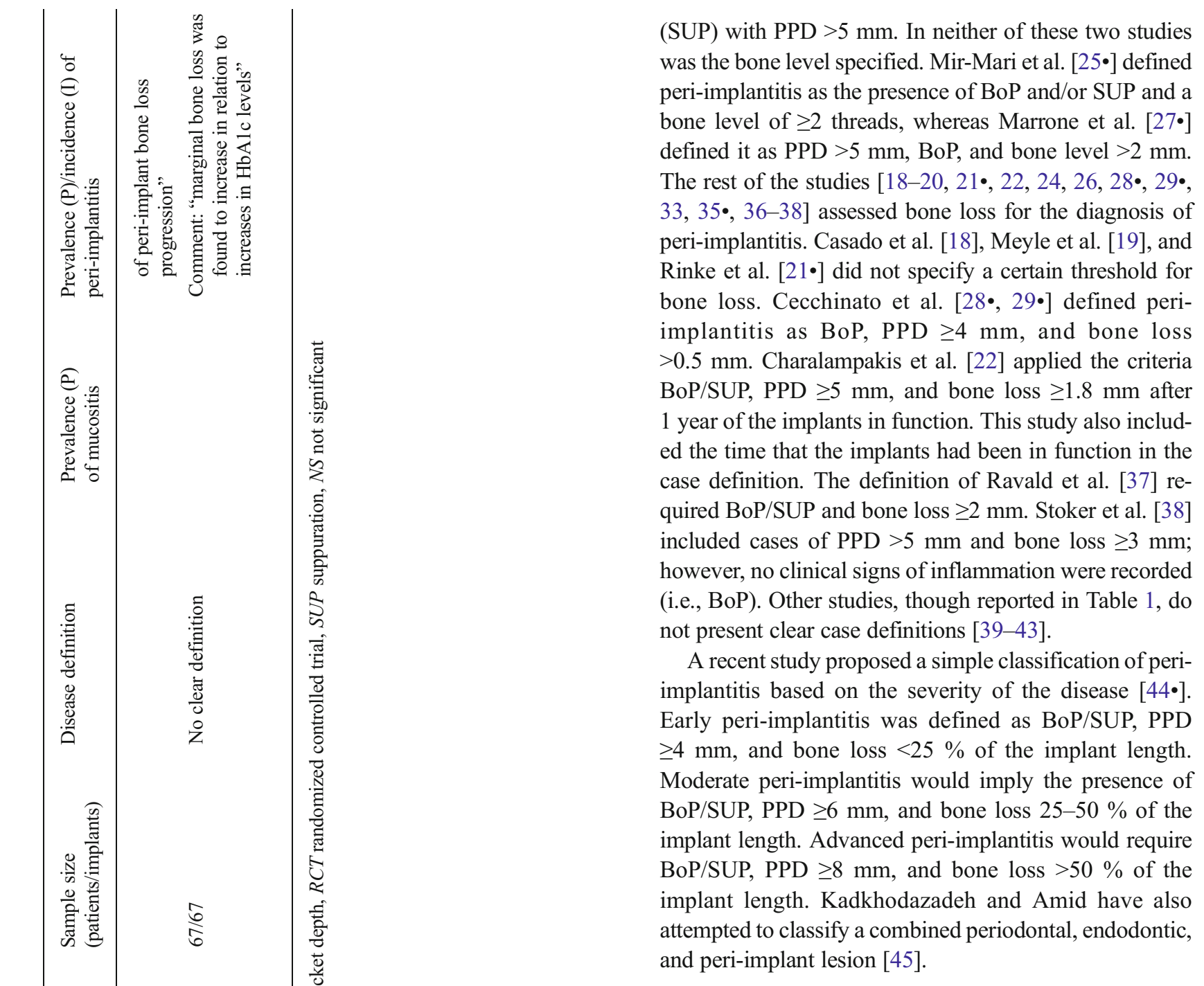

Prevalence of Peri-Implant Mucositis and Peri-Implantitis

It is well-accepted that the prevalence/incidence of a disease should be based on subject-level analysis, as it is the subject and not the site (implant) suffering from the disease independently. Implants in the same patient cannot be independent from each other and data extracted at an implant level should be considered as clustered data with all the relevant limitations [46-]. With regard to the prevalence and incidence of periimplant disease (Tables 1 and 2), cross-sectional and longitudinal studies should be included, respectively [47•]. All studies included on prevalence that are highlighted are of a crosssectional design, demonstrate a clear case definition, and present patient-level results.

The various definitions of peri-implant disease including different clinical and radiological thresholds would exert a significant influence on the magnitude of the reported prevalence/incidence of peri-implantitis. Another factor that can affect the frequency of disease is the type of population 
Table 2 Reviews and consensus reports 2011-2014 (N=13)

\begin{tabular}{|c|c|c|}
\hline References & $\begin{array}{l}\text { Type of } \\
\text { report }\end{array}$ & Comments/conclusions \\
\hline $\begin{array}{l}\text { Lang and Berglundh } \\
2011[11 \bullet]\end{array}$ & Consensus & $\begin{array}{l}\text { "Clinical and radiographic data should routinely be obtained after prosthesis installation on implants in order } \\
\text { to establish baseline for the diagnosis of peri-implantitis during maintenance of implant patients" }\end{array}$ \\
\hline $\begin{array}{l}\text { Berglundh et al. } \\
2011[62]\end{array}$ & Review & $\begin{array}{l}\text { "Despite similarities regarding clinical features and aetiology of peri-implantitis and periodontitis, critical } \\
\text { histopathological differences exist between the two lesions" }\end{array}$ \\
\hline $\begin{array}{l}\text { Klinge \& Meyle } \\
2012[63 \cdot \bullet]\end{array}$ & Consensus & $\begin{array}{l}\text { "Differences in the definition of peri-implantitis have resulted in a wide range of prevalence values" } \\
\text { "Early peri-implant bone resorption can be caused by remodeling" } \\
\text { "Long-term monitoring of implant performance should be based on radiographs taken directly after implant } \\
\text { placement, but should rather relate to recordings obtained } 3 \text { months after completion of treatment, once } \\
\text { homeostasis has been established" } \\
\text { "Peri-implantitis may be expected to occur in one of five patients, hence frequent monitoring of the } \\
\text { peri-implant tissues for signs of inflammation is necessary" }\end{array}$ \\
\hline Klinge 2012 [46•] & Review & $\begin{array}{l}\text { "...it is likely that the academic controversy in relation to peri-implant bone loss and peri-implantitis will } \\
\text { continue" }\end{array}$ \\
\hline $\begin{array}{l}\text { Mombelli et al. } \\
2012[49 \bullet]\end{array}$ & Review & $\begin{array}{l}\text { "...the prevalence of peri-implantitis seems to be in order of } 10 \% \text { implants and } 20 \% \text { patients during } \\
5-10 \text { years after implantation..." }\end{array}$ \\
\hline $\begin{array}{l}\text { Sanz and Chapple } \\
2012[53 \bullet]\end{array}$ & Consensus & $\begin{array}{l}\text { "In the absence of previous radiographic records to assess progressive bone loss, a threshold vertical distance } \\
\text { of } 2 \mathrm{~mm} \text { from the expected marginal bone level following remodeling post-implant placement is } \\
\text { recommended, to assess progressive bone loss." }\end{array}$ \\
\hline $\begin{array}{l}\text { Tomasi and Derks } \\
2012[47 \bullet]\end{array}$ & Review & “...need for improved reporting on epidemiological studies on peri-implant diseases" \\
\hline $\begin{array}{l}\text { American Academy of } \\
\text { Periodontology } \\
2013[64 \cdot]\end{array}$ & Consensus & $\begin{array}{l}\text { "...routine monitoring of dental implants as a part of comprehensive periodontal evaluation and } \\
\text { maintenance is essential" } \\
\text { - Identify risk factors associated with developing peri-implant diseases } \\
\text { - Establish radiographic baseline at time of implant placement } \\
\text { - Establish clinical and radiographic baseline at final prosthesis insertion } \\
\text { - Employ methods that monitor implant health and determine inflammatory complications as part of an } \\
\text { ongoing maintenance program } \\
\text { - Establish an early diagnosis and intervention, which will contribute to more effective management of } \\
\text { peri-implant diseases }\end{array}$ \\
\hline Atieh et al. 2013 [48•] & Review & $\begin{array}{l}\text { Prevalence (patients/implants): } \\
\text { Mucositis: } 63.3 \% / 30.7 \% \\
\text { Peri-implantitis: } 18.8 \% / 9.6 \% \\
\text { "Peri-implant diseases are not uncommon following implant therapy. Long-term maintenance care for } \\
\text { high-risk groups is essential to reduce risk of peri-implantitis." }\end{array}$ \\
\hline De Bruyn et al. 2013 [65] & Review & $\begin{array}{l}\text { "If defining peri-implantitis as 'infection with suppuration associated with clinically significant progressing } \\
\text { crestal bone loss' the disease incidence according to recent longitudinal studies on modern surfaces is }<5 \% \\
\text { after } 10 \text { years in function" }\end{array}$ \\
\hline Murray et al. 2013 [66] & Review & $\begin{array}{l}\text { "Well-defined criteria should be used for the assessment and correct diagnosis of peri-implant disease." } \\
\text { "...the key to maintaining peri-implant tissue health is continuous assessment and the provision of } \\
\text { individualized supported treatment" }\end{array}$ \\
\hline $\begin{array}{l}\text { Heitz-Mayfield et al. } \\
2014[60 \bullet \cdot]\end{array}$ & Consensus & $\begin{array}{l}\text { Diagnosis: } \\
\text { Peri-implant mucositis: "clinical signs of soft tissue inflammation (eg, redness, edema, suppuration) and } \\
\text { bleeding on gentle probing" } \\
\text { Peri-implantitis: "presence of mucositis in conjunction with progressive crestal bone loss" }\end{array}$ \\
\hline Pesce et al. 2014 [67] & Review & "...both the choice of the term peri-implantitis and its definition remain controversial" \\
\hline
\end{tabular}

included in the study (general or specific). Certain groups of patients might be of higher risk and the prevalence of periimplant disease should be expected to increase in such individuals. A recent systematic review with meta-analysis [48•] concluded that the frequency of peri-implant mucositis was $63.4 \%$ on the patient level and $30.7 \%$ on the implant level. Corresponding figures for peri-implantitis were 18.8 and $9.6 \%$. For smokers, a group considered to be high risk, the frequency of peri-implantitis increased to $36.3 \%$. In another review of a narrative nature on the epidemiology of peri-implantitis, it was similarly stated that the prevalence of peri-implantitis over a 5- to 10-year period following implant placement is in the order of $10 \%$ of implants and $20 \%$ of patients [49•]. Below, we discuss the prevalence figures separately for the two forms of peri-implant disease. 
a) Peri-Implant Mucositis

The prevalence of peri-implant mucositis at the patient level was reported in six studies and varied between 1.1 and $80 \%[20,21 \cdot, 22,25 \bullet, 27 \bullet, 32]$.

b) Implantitis

The prevalence of peri-implantitis at the patient level was assessed in 12 studies and ranged from 1.4 to $53.3 \%$ [18-20, 21•, 23•, 25•, 27•, 28•, 29•, 32, 34•, 36].

\section{Discussion}

The Problem with a Case Definition of Peri-Implant Disease

We have been facing a lack of consensus on a case definition of peri-implant disease. This is not surprising as we have encountered similar difficulties in the case of periodontitis. It has been shown that a major limiting factor in determining and comparing prevalence estimates of periodontitis across surveys is the lack of a universally accepted case definition for periodontitis $[50,51]$. There is no agreement on the cut-off points for different levels of disease. Similar to periodontal disease [52], peri-implant disease does not seem to hold any diagnostic truth, in the sense that there is no natural basis for a clear distinction between different severity levels of disease.

An additional problem, inherent in the case of the dental implant, is that the position of the implant in the oral cavity is not biologically determined, implying that the acceptable bone level around an implant in function may not always be analogous to the $2 \mathrm{~mm}$ distance from the cementoenamel junction, the standard reference point in the case of the tooth. In order to assess bone level changes accurately, we need baseline radiological images. As reported in a recent consensus [53•], "in the absence of previous radiographic records, a threshold vertical distance of $2 \mathrm{~mm}$ from the expected marginal bone level following remodeling post-implant placement is recommended, provided peri-implant inflammation is evident".

Another issue is the starting point for monitoring bonelevel changes around an implant. Given that a dental implant, though osseointegrated with the host, is still a 'foreign body', some bone loss during the tissue homeostasis period for the first year of an implant being in function should be accepted. Most authors accept a marginal bone loss in the first year after implant placement of 1.5-2 mm [54-56]. As early as 1986, it was claimed that tissue stability is expected at 1 year after placement and that a continuous bone loss of more than $0.2 \mathrm{~mm}$ per year was undesirable [55]. It has been advocated that marginal bone loss around the neck of implants should be considered a remodeling phenomenon, not only some months after loading but continuously [56]. Thus, continuous bone loss was regarded as a natural bone remodeling process rather than a pathological condition. In a prospective study, it was demonstrated that bone remodeling continued for 6 months, after which no further changes were observed [57]. It should therefore be expected that the bone remodeling process occurs within a few months and terminates as soon as the biological width is established.

For the diagnosis of peri-implant mucositis, clinical features are sufficient. However, for peri-implantitis we not only need a combination of clinical and radiological features for a correct diagnosis, we additionally need evidence for progressive bone loss. There are cases where suboptimal bone levels are depicted on the $\mathrm{x}$-rays in conjunction with $\mathrm{BoP}$ and PPD. However, this could be a result of suboptimal bone levels at the time of implant insertion or subcrestal implant placement for aesthetic reasons [58] and not a result of an infectious disease. In addition, certain implant designs create 'pseudopockets' by creating a distance from the implant shoulder to the mucosal margin of up to $5 \mathrm{~mm}$ [59].

A recent consensus statement $[60 \bullet$ ] required the presence of mucositis in conjunction with progressive crestal bone loss to diagnose peri-implantitis. However, universally accepted thresholds for bone loss and pocket depth are unavailable. The same consensus concluded that "the case definition of peri-implantitis remains unclear and varies substantially between studies". This variance in the case definition of periimplantitis results in the inclusion of heterogenous studies, which has a negative impact on disease epidemiology. All included studies in the current review report prevalence figures of peri-implant disease. There are only two available studies presenting data on the incidence of peri-implantitis $[29 \bullet, 61 \bullet]$. Cecchinato et al. [29•] reported the incidence of peri-implantitis over a 10 -year period as being $12 \%$ of patients, whereas an earlier 5 -year follow-up study [61 •] reported peri-implantitis at a level of $1 \%$ according to the specific case definition used. To our knowledge, only one study has been published on the incidence of peri-implant mucositis to date in the literature [32]. This study demonstrated that with stringent maintenance, the incidence of peri-implant mucositis was less than $10 \%$.

\section{Conclusions}

Peri-implant disease is undoubtedly a reality in clinical practice. However it has some 'gray zones' with unanswered questions that require further investigation. Therefore, in some cases there is a current dilemma for both the patient and dental practitioner as to whether or not to take action regarding peri-implantitis.

A universally accepted case definition for peri-implantitis is mandatory for both clinicians and researchers. It is fundamental not only for clinicians to speak the same language when they define a peri-implantitis case but also for researchers in order to compare different studies and come up 
with robust conclusions in meta-analysis. This has not happened so far and needs to change. To reach a consensus on case definition would have two additional advantages. First, the true prevalence of peri-implantitis would be reported with a slighter discrepancy among studies, giving clear answers on whether peri-implantitis is a problem in clinical reality or not. In addition, homogenous figures on the successful outcome of peri-implantitis therapy would be achieved, as similar thresholds for the therapy goals would be used in the studies performed.

The case definition of peri-implantitis should be kept as simple as possible. We would assign a case as peri-implantitis on the conditions that (a) presence of BoP and/or suppuration is recorded and (b) progressive bone loss is clearly shown on radiographs. We recommend additional classification of the case as mild, moderate, or severe because this would have a direct impact on the treatment modalities to be used. We should bear in mind that PPD may not reflect disease severity in all cases and setting thresholds based on PPD may under-/ overestimate the clinical problem. Having said this, bone loss in relation to the implant length is a better marker for characterizing the case as mild/moderate or severe peri-implantitis. Early diagnosis and correct classification is critical in order to stop future progressive bone loss by taking action accordingly. Peri-implantitis is unpredictable to treat and late therapeutic intervention may lead to implant loss.

\section{Compliance with Ethic Guidelines}

Conflict of Interest Dr. Ann-Marie Roos-Jansåker, Dr. Georgios Charalampakis, and Stud. Odont. Erika Jansåker each declare that they have no conflict of interest.

Human and Animal Rights and Informed Consent No human or animal studies performed by the authors:

This article does not contain any studies with human or animal subjects performed by any of the authors.

\section{References}

Papers of particular interest, published recently, have been highlighted as:

- Of importance

•- Of major importance

1. Branemark PI, Hansson BO, Adell R, Breine U, Lindstrom J, Hallen $\mathrm{O}$, et al. Osseointegrated implants in the treatment of the edentulous jaw. Experience from a 10-year period. Scand J Plast Reconstr Surg Suppl. 1977;16:1-132.

2. Adell R, Eriksson B, Lekholm U, Branemark PI, Jemt T. Long-term follow-up study of osseointegrated implants in the treatment of totally edentulous jaws. Int J Oral Maxillofac Implants. 1990;5:347-59.

3. Aglietta M, Siciliano VI, Zwahlen M, Bragger U, Pjetursson BE, Lang NP, et al. A systematic review of the survival and complication rates of implant supported fixed dental prostheses with cantilever extensions after an observation period of at least 5 years. Clin Oral Implants Res. 2009;20:441-51.

4. Lekholm U, Grondahl K, Jemt T. Outcome of oral implant treatment in partially edentulous jaws followed 20 years in clinical function. Clin Implant Dent Relat Res. 2006;8:178-86.

5. Simonis P, Dufour T, Tenenbaum H. Long-term implant survival and success: a 10-16-year follow-up of non-submerged dental implants. Clin Oral Implants Res. 2010;21:772-7.

6. Klinge B, Hultin M, Berglundh T. Peri-implantitis. Dent Clin N Am. 2005;49:661-76.

7. Levignac J. Periimplantation osteolysis- periimplantosis periimplantitis. Rev Fr Odontostomatol. 1965;12:1251-60.

8. Mombelli A, Muller N, Cionca N. The microbiota associated with successful or failing osseointegrated titanium implants. Oral Microbiol Immunol. 1987;2:145-51.

9. Albrektsson T, Isidor F. Consensus Report: Implant Therapy. In: Proceedings of the 1st European Workshop on Periodontology. Berlin: Quintessence; 1994.

10. Lindhe J, Meyle J. Peri-implant diseases: consensus report of the sixth European workshop on Periodontology. J Clin Periodontol. 2008;35:282-5.

11. Lang NP, Berglundh T. Periimplant diseases: where are we now?consensus of the Seventh European workshop on periodontology. J Clin Periodontol. 2011;38:178-81. In this consensus report it is agreed that routine clinical and radiographic recordings are essential after prosthesis installation on implants to establish a baseline for correct diagnosis of potential peri-implantitis in the future.

12. Zitzmann NU, Berglundh T. Definition and prevalence of periimplant diseases. J Clin Periodontol. 2008;35:286-91.

13. Ferreira SD, Silva GL, Cortelli JR, Costa JE, Costa FO. Prevalence and risk variables for peri-implant disease in Brazilian subjects. J Clin Periodontol. 2006;33:929-35.

14. Fransson C, Wennstrom J, Berglundh T. Clinical characteristics at implants with a history of progressive bone loss. Clin Oral Implants Res. 2008;19:142-7.

15. Koldsland OC, Scheie AA, Aass AM. Prevalence of periimplantitis related to severity of the disease with different degrees of bone loss. J Periodontol. 2010;81:231-8. This study demonstrates that assessing peri-implantitis at different thresholds of bone loss yields substantial variance in the prevalence of the disease.

16. Maximo MB, de Mendonca AC, Alves JF, Cortelli SC, Peruzzo DC, Duarte PM. Peri-implant diseases may be associated with increased time loading and generalized periodontal bone loss: preliminary results. J Oral Implantol. 2008;34:268-73.

17. Roos-Jansåker AM, Lindahl C, Renvert H, Renvert S. Nine- to fourteen-year follow-up of implant treatment. Part II: presence of peri-implant lesions. J Clin Periodontol. 2006;33:290-5.

18. Casado PL, Pereira MC, Duarte ME, Granjeiro JM. History of chronic periodontitis is a high risk indicator for peri-implant disease. Braz Dent J. 2013;24:136-41.

19. Meyle J, Gersok G, Boedeker RH, Gonzales JR. Long-term analysis of osseointegrated implants in non-smoker patients with a previous history of periodontitis. J Clin Periodontol. 2014;41:504-12.

20. Casado PL, Villas-Boas R, de Mello W, Duarte ME, Granjeiro JM. Peri-implant disease and chronic periodontitis: is interleukin- 6 gene promoter polymorphism the common risk factor in a Brazilian population? Int J Oral Maxillofac Implants. 2013;28:35-43.

21. Rinke S, Ohl S, Ziebolz D, Lange K, Eickholz P. Prevalence of periimplant disease in partially edentulous patients: a prevalence of periimplant disease in partially edentulous patients: a practice-based cross-sectional study. Clin Oral Implants Res. 2011;22:826-33. This study demonstrates that no peri-implantitis was diagnosed in nonsmokers with no periodontal history and with good maintenance care.

22. Charalampakis G, Leonhardt A, Rabe P, Dahlen G. Clinical and microbiological characteristics of peri-implantitis cases: a retrospective multicentre study. Clin Oral Implants Res. 2012;23:1045-54. 
23. Costa FO, Takenaka-Martinez S, Cota LO, Ferreira SD, Silva GL, Costa JE. Peri-implant disease in subjects with and without preventive maintenance: a 5-year follow-up. J Clin Periodontol. 2012;39(2):173-81. This study analyses a subset of a previous study (Ferreira et al., 2006) and presents clear data on prevalence of peri-implant diseases.

24. Lopez-Piriz R, Morales A, Gimenez MJ, Bowen A, Carroquino R, Aguilar L, et al. Correlation between clinical parameters characterising peri-implant and periodontal health: a practicebased research in Spain in a series of patients with implants installed 4-5 years ago. Med Oral Patol Oral Cir Bucal. 2012;17:893-901.

25. Mir-Mari J, Mir-Orfila P, Figueiredo R, Valmaseda-Castellon E, Gay-Escoda C. Prevalence of peri-implant diseases. A crosssectional study based on a private practice environment. J Clin Periodontol. 2012;39:490-4. This study presents patient-based prevalence figures of peri-implant diseases from Spanish patients enrolled in private practice.

26. Rodrigo D, Martin C, Sanz M. Biological complications and periimplant clinical and radiographic changes at immediately placed dental implants. A prospective 5-year cohort study. Clin Oral Implants Res. 2012;23:1224-31.

27. Marrone A, Lasserre J, Bercy P, Brecx MC. Prevalence and risk factors for peri-implant disease in Belgian adults. Clin Oral Implants Res. 2013;24:934-40. This study reports data on the frequency of peri-implant diseases and identifies possible risk indicators for peri-implantitis.

28. Cecchinato D, Parpaiola A, Lindhe J. A cross-sectional study on the prevalence of marginal bone loss among implant patients. Clin Oral Implants Res. 2013;24:87-90. This study investigates the amount of bone loss in subjects with implant-supported prostheses and reports the prevalence and severity figures of peri-implantitis in a subsample.

29. Cecchinato D, Parpaiola A, Lindhe J. Mucosal inflammation and incidence of crestal bone loss among implant patients: a 10-year study. Clin Oral Implants Res. 2014;25:791-6. This longitudinal study provides incidence figures for marginal bone loss and periimplantitis in subjects having implants in function for 10 years.

30. Roccuzzo M, Bonino F, Aglietta M, Dalmasso P. Ten-year results of a three arms prospective cohort study on implants in periodontally compromised patients. Part 2: clinical results. Clin Oral Implants Res. 2012;23:389-95.

31. Roccuzzo ML, Bonino F, Dalmasso P, Aglietta M. Long-term results of a three arms prospective cohort study on implants in periodontally compromised patients: 10 -year data around sandblasted and acid-etched (SLA) surface. Clin Oral Implants Res. 2013.

32. Corbella S, Del Fabbro M, Taschieri S, De Siena F, Francetti L. Clinical evaluation of an implant maintenance protocol for the prevention of peri-implant diseases in patients treated with immediately loaded full-arch rehabilitations. Int J Dent Hyg. 2011;9:216-22.

33. Lee JS, Kim HM, Kim CS, Choi SH, Chai JK, Jung UW. Long-term retrospective study of narrow implants for fixed dental prostheses. Clin Oral Implants Res. 2012.

34. Dvorak G, Arnhart C, Heuberer S, Huber CD, Watzek G, Gruber R. Peri-implantitis and late implant failures in postmenopausal women: a cross-sectional study. J Clin Periodontol. 2011;38:950-5. This cross-sectional study evaluates the correlation between selfreported osteoporosis and the success rate of dental implants in an adult female population in Austria.

35. Fischer K, Stenberg T. Prospective 10-year cohort study based on a randomized controlled trial (RCT) on implant-supported full-arch maxillary prostheses. Part 1: sandblasted and acid-etched implants and mucosal tissue. Clin Implant Dent Relat Res. 2012;14:808-15. This cohort study is one of the few reporting 10-year data on implants with a sandblasted and acid-etched surface placed in the edentulous maxilla.
36. Gotfredsen K. A 10-year prospective study of single tooth implants placed in the anterior maxilla. Clin Implant Dent Relat Res. 2012;14:80-7.

37. Ravald N, Dahlgren S, Teiwik A, Grondahl K. Long-term evaluation of Astra Tech and Branemark implants in patients treated with full-arch bridges. Results after 12-15 years. Clin Oral Implants Res. 2013;24:1144-51.

38. Stoker G, van Waas R, Wismeijer D. Long-term outcomes of three types of implant-supported mandibular overdentures in smokers. Clin Oral Implants Res. 2012;23:925-9.

39. Buser D, Janner SF, Wittneben JG, Bragger U, Ramseier CA, Salvi GE. 10-year survival and success rates of 511 titanium implants with a sandblasted and acid-etched surface: a retrospective study in 303 partially edentulous patients. Clin Implant Dent Relat Res. 2012;14:839-51.

40. Ostman PO, Hellman M, Sennerby L. Ten years later. Results from a prospective single-centre clinical study on 121 oxidized (TiUnite) Branemark implants in 46 patients. Clin Implant Dent Relat Res. 2012;14:852-60.

41. Dierens M, Vandeweghe S, Kisch J, Persson GR, Cosyn J, De Bruyn H. Long-term follow-up of turned single implants placed in periodontally healthy patients after 16 to 22 years: microbiologic outcome. J Periodontol. 2013;84:880-94.

42. Galindo-Moreno P, León-Cano A, Ortega-Oller I, Monje A, Valle OF, Catena A. Marginal bone loss as success criterion in implant dentistry: beyond $2 \mathrm{~mm}$. Clin Oral Implants Res.

43. Gómez-Moreno G, Aguilar-Salvatierra A, Rubio Roldán J, Guardia J, Gargallo J, Calvo-Guirado JL. Peri-implant evaluation in type 2 diabetes mellitus patients: a 3-year study. Epub: Clin Oral Implants Res; 2014.

44. Froum SJ, Rosen PS. A proposed classification for peri-implantitis. Int J Periodontics Restor Dent. 2012;32:533-40. This paper prooses, for the first time, classification of peri-implantitis based on the severity of the disease.

45. Kadkhodazadeh M, Amid R. A New classification for the relationship between periodontal, periapical, and peri-implant complications. Iran Endod J. 2013;8:103-8.

46. Klinge B. Peri-implant marginal bone loss: an academic controversy or a clinical challenge? Eur J Oral ImplantoL. 2012;5(Suppl):S13-9. This review paper suggests that composite variables including bone loss $\geq 2 \mathrm{~mm}$ compared with initial radiograph at the delivery of prosthodontic device in combination with BoP should be interpreted as a red flag for the clinician.

47. Tomasi C, Derks J. Clinical research of peri-implant diseases - quality of reporting, case definitions and methods to study incidence, prevalence and risk factors of peri-implant diseases. J Clin Periodontol. 2012;39:207-23. This review paper assesses the quality of reporting on the incidence, prevalence, and risk factors of peri-implant diseases using the STROBE (STrengthening the Reporting of OBservational studies in Epidemiology) checklist.

48. Atieh MA, Alsabeeha NH, Faggion Jr CM, Duncan WJ. The frequency of peri-implant diseases: a systematic review and metaanalysis. J Periodontol. 2013;84:1586-98. This review systematically evaluates the frequency of peri-implant diseases in general and high-risk patients.

49. Mombelli A, Muller N, Cionca N. The epidemiology of periimplantitis. Clin Oral Implants Res. 2012;23:67-76. This review paper focuses on the incidence and prevalence of peri-implantitis and explains why terminology may not always concide with a case definition.

50. Eke PI, Page RC, Wei L, Thornton-Evans G, Genco RJ. Update of the case definitions for population-based surveillance of periodontitis. J Periodontol. 2012;83:1449-54. 
51. Eke PI, Thornton-Evans GO, Wei L, Borgnakke WS, Dye BA. Accuracy of NHANES periodontal examination protocols. J Dent Res. 2010;89:1208-13.

52. Lopez R, Baelum V. Classifying periodontitis among adolescents: implications for epidemiological research. Community Dent Oral Epidemiol. 2003;31:136-43.

53. Sanz M, Chapple IL. Clinical research on peri-implant diseases: consensus report of Working Group 4. J Clin Periodontol. 2012;39: 202-6. This consensus gives guidelines to clinicians and researchers for assessing progressive bone loss in the absence of previous radiographic records.

54. Papaspyridakos P, Chen CJ, Singh M, Weber HP, Gallucci GO. Success criteria in implant dentistry: a systematic review. J Dent Res. 2012;91:242-8.

55. Albrektsson T, Zarb G, Worthington P, Eriksson AR. The long-term efficacy of currently used dental implants: a review and proposed criteria of success. Int $\mathrm{J}$ Oral Maxillofac Implants. 1986;1:11-25.

56. Jemt T, Albrektsson T. Do long-term followed-up Branemark implants commonly show evidence of pathological bone breakdown? A review based on recently published data. Periodontol 2000. 2008;47:133-42.

57. Vandeweghe S, Hattingh A, Wennerberg A, Bruyn HD. Surgical protocol and short-term clinical outcome of immediate placement in molar extraction sockets using a wide body implant. J Oral MaxillofaccRes. 2011;2:e1.

58. Hammerle $\mathrm{CH}$, Bragger U, Burgin W, Lang NP. The effect of subcrestal placement of the polished surface of ITI implants on marginal soft and hard tissues. Clin Oral Implants Res. 1996;7:111-9.

59. Gallucci GO, Grutter L, Chuang SK, Belser UC. Dimensional changes of peri-implant soft tissue over 2 years with singleimplant crowns in the anterior maxilla. J Clin Periodontol. 2011;38:293-9.
60.• Heitz-Mayfield LJ, Needleman I, Salvi GE, Pjetursson BE. Consensus statements and clinical recommendations for prevention and management of biologic and technical implant complications. Int J Oral Maxillofac Implants. 2014;29(Suppl):346-50. This consensus report addresses guidelines for clinicians to prevent and manage peri-implantitis.

61. Zetterqvist L, Feldman S, Rotter B, Vincenzi G, Wennstrom JL, Chierico A, et al. A prospective, multicenter, randomized-controlled 5 -year study of hybrid and fully etched implants for the incidence of peri-implantitis. J Periodontol. 2010;81:493-501. This is the first study presenting data on the incidence of peri-implantitis.

62. Berglundh T, Zitzmann NU, Donati M. Are peri-implantitis lesions different from periodontitis lesions? J Clin Perio. 2011;38 Suppl 11: 188-202.

63.• Klinge B, Meyle J. Peri-implant tissue destruction. The Third EAO Consensus Conference 2012. Clin Oral Implants Res. 2012;23 Suppl 6:108-10. This paper points to clinical and radiographical thresholds, summarized by statements agreed upon at the consensus conference.

64. The American Academy of Periodontology. Peri-implant mucositis and peri-implantitis: a current understanding of their diagnoses and clinical implications. J Periodontol. 2013;84:436-43. This review focuses on diagnostic markers, risk factors, and the etiopathogenesis of peri-implantitis.

65. De Bruyn H, Vandeweghe S, Ruyffelaert C, Cosyn J, Sennerby L. Radiographic evaluation of modern oral implants with emphasis on crestal bone level and relevance to peri-implant health. Periodontol 2000. 2013; 62:256-270.

66. Murray CM, Knight ET, Russell AA, Tawse-Smith A, Leichter JW. Peri-implant disease: current understanding and future direction. N Z Dent J. 2013;109:55-62.

67. Pesce P, Menini M, Tealdo T, Bevilacqua M, Pera F, Pera P. Periimplantitis: a systematic review of recently published papers. Int J Prosthodont. 2014;27:15-25. 